\title{
Histidine and other amino acids in blood and urine after administration of Bretschneider solution (HTK) for cardioplegic arrest in patients: effects on $\mathrm{N}$-metabolism
}

\author{
Johanna K. Teloh ${ }^{1} \cdot$ Daniel-Sebastian Dohle $^{2} \cdot$ Miriam Petersen $^{3} \cdot$ Rabea Verhaegh $^{1} \cdot$ \\ Indra N. Waack ${ }^{1} \cdot$ Friederike Roehrborn $^{1} \cdot$ Heinz Jakob $^{2} \cdot$ Herbert de Groot $^{1}$
}

Received: 24 November 2015 / Accepted: 6 February 2016 / Published online: 27 February 2016

(c) The Author(s) 2016. This article is published with open access at Springerlink.com

\begin{abstract}
Bretschneider (histidine-tryptophan-ketoglutarate, HTK) solution employed for induction of cardioplegic arrest possesses a high histidine concentration $(198 \mathrm{mM})$. Due to the large volume administered, massive amounts of histidine are incorporated. The aim of the study was to evaluate alterations in amino acid and nitrogen metabolism originating from histidine degradation. Between 07/2014 and 10/2014, a total of 29 consecutive patients scheduled for elective isolated coronary artery bypass grafting with cardiopulmonary bypass (CPB) were enrolled in this prospective observational study. The patients received $1.6 \mathrm{~L}$ cardioplegic Bretschneider solution on average. Blood gas and urine samples obtained were analyzed for amino acid as well as urea and ammonium concentrations. After CPB initiation, plasma histidine concentration greatly increased to $21,000 \mu \mathrm{M}$ to reach $8000 \mu \mathrm{M}$ at the end. Within the operative period, plasma concentrations of aspartate, glutamate, asparagine, alanine, and glutamine increased variable in magnitude. During the same time, urinary analysis revealed histidine excretion of $19,500 \mu \mathrm{mol}$ in total and marked
\end{abstract}

Handling Editor: C.-A. A. Hu. elevations in glutamate and glutamine excretion. The absolute amounts of urea and ammonium excreted additionally were $3 \mathrm{mmol}$ and $8 \mathrm{mmol}$, respectively. Already during $\mathrm{CPB}$, distinct amounts of the histidine administered are metabolized, mainly to other amino acids, but only small amounts to urea and ammonia. Thus, the impact of the histidine incorporated on acid-base status in the intraoperative phase is minor. On the other hand, intraoperative provision of several amino acids arising from histidine metabolism might mitigate postaggression syndrome.

Keywords Cardioplegia - Cardiopulmonary bypass . Heart-lung machine $\cdot$ Inzolen

\section{Introduction}

Bretschneider (histidine-tryptophan-ketoglutarate, HTK) solution is routinely administered for cardioplegic arrest in many countries (Careaga et al. 2001). In clinical studies as well as in experimental models the Bretschneider solution has

Friederike Roehrborn

froehrborn@gmail.com

Heinz Jakob

heinz.jakob@uk-essen.de

Institute of Physiological Chemistry, University Hospital Essen, University of Duisburg-Essen, Hufelandstraße 55, 45122 Essen, Germany

2 Department of Thoracic and Cardiovascular Surgery, University Hospital Essen, Hufelandstraße 55, 45122 Essen, Germany

3 Ambulatory Healthcare Center MVZ Dr. Eberhard und Partner, Brauhausstraße 4, 44137 Dortmund, Germany 
been shown to achieve a better myocardial protection during ischemia as compared to pure electrolyte-containing crystalloid cardioplegic solutions without histidine or to blood cardioplegia (Beyersdorf et al. 1990; Careaga et al. 2001; Kober et al. 1998; Korun et al. 2013; Sakata et al. 1998; Scrascia et al. 2011). The effectiveness of the solution becomes apparent in an increased cardiac output, fewer arrhythmias, more frequent spontaneous defibrillation as well as decreasing length of stay in the intensive care unit (Careaga et al. 2001; Sakata et al. 1998). The included histidine (198 mM) is associated with enhanced efficiency of anaerobic glycolysis due to a high buffer capacity, whereas $\alpha$-ketoglutarate $(1 \mathrm{mM})$, an intermediary of the Krebs cycle, is assumed to serve energy production. Tryptophan $(2 \mathrm{mM})$ and mannitol $(30 \mathrm{mM})$ are proposed to function as a stabilizer of cell membranes and to reduce cellular edema formation, respectively (Careaga et al. 2001). Usually, if Bretschneider solution is employed, almost all of the administered volume enters the systemic circulation. Thus, due to the large volume of the Bretschneider solution applied for induction of cardioplegic arrest, there is a massive incorporation of histidine.

To date, only very few data exist on plasma amino acid concentrations originating from histidine metabolism related to Bretschneider cardioplegia (Doetsch et al. 1987; Schayani-Mühlschlegel 1990). Therefore, we will here analyze concentrations of especially histidine but also further amino acids as well as urea and ammonia in plasma derived from intraoperatively taken blood gas samples as well as urine samples obtained at the beginning and the end of the operation, thus trying to establish an overall balance of amino acid and nitrogen metabolism under these conditions.

\section{Materials and methods}

\section{Study design and patient population}

Between 07/2014 and 10/2014, a total of 29 consecutive patients scheduled for elective isolated coronary artery bypass grafting (CABG) with cardiopulmonary bypass (CPB) were enrolled in the prospective observational designed study at the Department of Thoracic and Cardiovascular Surgery, University Hospital Essen. The study was approved by the Medical Ethics Committee of the University Hospital Essen and confirms to the principles of the Declaration of Helsinki. All individuals gave written informed consent. In short, myocardial protection was achieved using antegrade cold crystalloid Bretschneider cardioplegia (Custodiol, Dr. Franz Koehler Chemie, Bensheim, Germany), employing $1.6 \pm 0.2 \mathrm{~L}$ on average supplemented by topical cooling, and single aortic crossclamping for all distal anastomoses. After weaning from the heart-lung machine, patients received $56 \mathrm{~mL}$ Inzolen (Dr. Franz Koehler Chemie, Bensheim, Germany) on average. For further details see (Teloh et al. 2015).

\section{Patient Characteristics}

Of all patients, $76 \%$ were male gender. The median values for age, height, weight, cardiopulmonary bypass time, and cross-clamp-time were 71 years, $173 \mathrm{~cm}, 84 \mathrm{~kg}, 86 \mathrm{~min}$ and $53 \mathrm{~min}$, respectively. On average, patients received three grafts each.

\section{Data collection}

Blood gas samples were routinely taken during operative procedures (initially, after beginning of $\mathrm{CPB}$, before cessation of $\mathrm{CPB}$, after cessation of $\mathrm{CPB}$, before the end of operative procedures), and centrifuged at $3000 \mathrm{~g}$ for $10 \mathrm{~min}$ at room temperature. Subsequently, the plasma was taken off and stored at $-80{ }^{\circ} \mathrm{C}$ until analysis.

Immediately after catheterization of the patient's urinary bladder, a urine sample was obtained in order to represent baseline conditions. At the end of the operative procedures, a second sample was gathered from the volume that had been collected during the operation.

\section{Measurements}

For ammonium quantification in urine, capillary electrophoresis (P/ACE MDQ, Beckmann Coulter, Krefeld, Germany) was used. For this purpose, a fused silica capillary was employed with an effective length of $50 \mathrm{~cm}$, an I.D. of $75 \mu \mathrm{m}$ and an O.D. of $375 \mu \mathrm{m}$. Samples of initial urine were diluted with ultrapure water 1:50. Analysis was performed using a cation analysis kit (ABSciex, Fullerton, USA) and pressure injection. The subsequent separation proceeded using a voltage of $30 \mathrm{kV}$ and normal polarity of the capillary. Indirect detection was performed employing a photo diode array at a wavelength of $200 \mathrm{~nm}$. Due to the low sensitivity of the employed capillary electrophoresis, ammonium quantification in plasma was performed with an enzymatic method in the central laboratory of the University Hospital Essen.

Urine and plasma were analyzed for urea. Plasma samples were diluted 1:4, whereas urine was diluted 1:10 with $0.9 \% \mathrm{NaCl}$. Urea was determined with the help of a fully automated clinical chemistry analyzer (Respons 920, DiaSys Diagnostics, Holzheim, Germany) using a commercially available reagent (DiaSys Diagnostics, Holzheim, Germany) for the enzymatic reactions of urease and glutamate dehydrogenase and subsequent detection of NADH decrease at $340 \mathrm{~nm}$.

Urine and plasma samples were also analyzed for amino acids. For deproteinization, $300 \mu \mathrm{L}$ sample were 
added to $75 \mu \mathrm{L}$ sulfosalicylic acid (10\% in water) and thoroughly mixed. This mixture was centrifuged at $12,000 \mathrm{U} / \mathrm{min}$ for $5 \mathrm{~min}$. Subsequently, $200 \mu \mathrm{L}$ of the supernatant were diluted with reagent buffer at the ratio of $1: 1$. Of this formulation, $50 \mu \mathrm{L}$ were injected into the liquid chromatograph (biochrom $30+$, biochrom, Cambridge, UK). With the help of the employed cation exchanger, separation of amino acids took place at a rate of $0.25 \mathrm{~mL} / \mathrm{min}$ due to varying $\mathrm{pH}$ and molarity of used running buffers containing citrate. Following this, the amino group reacted with ninhydrin, forming a colored complex which was detected at $570 \mathrm{~nm}$ (primary amino acids) and $440 \mathrm{~nm}$ (secondary amino acids), respectively. Urine as well as plasma samples were treated in the same way. Due to technical limitations in association with the high histidine concentration in plasma subsequent to Bretschneider application, tryptophan could not be exactly quantified.

\section{Statistical analysis}

All data are expressed as mean values \pm standard deviation (SD) unless otherwise stated. Comparisons among different time points were performed using one-way independent analysis of variance (ANOVA) followed by the Fisher (LSD) post hoc analysis. A $P$ value $<0.05$ was considered significant.

\section{Results}

After start of CPB with concomitant induction of cardioplegic arrest, plasma histidine concentration sharply increased from an initial value of 71 to $21000 \mu \mathrm{M}$ (Fig. 1a). Subsequently, during the course of the operation, it steadily decreased, reaching a concentration of $8000 \mu \mathrm{M}$ at the end. The aspartate's concentration in plasma rose from $5 \mu \mathrm{M}$ before to $1600 \mu \mathrm{M}$ at the end of operation (Fig. 1b). Within the same interval, plasma glutamate concentration increased from 23 to $360 \mu \mathrm{M}$ (Fig. 1c). Plasma concentrations of glutamine, asparagine, glycine, alanine and serine rose modestly from initial values of 596, 38, 214, 318, and $108 \mu \mathrm{M}$, respectively, to $862,65,325,807$, and $174 \mu \mathrm{M}$, respectively, at the end of the operation (Figs. 1d, 2a-d). Plasma concentrations of arginine, leucine, lysine, methionine, ornithine, phenylalanine, proline, tyrosine, threonine as well as valine varied little, and stayed within the respective reference ranges (Table 1).

Histidine excretion largely increased from $47 \mu \mathrm{mol} /$ mmol creatinine at basal conditions to $6760 \mu \mathrm{mol} /$ mmol creatinine at the end of operation (Fig. 3a). Taking the intraoperatively excreted urine volume into account, it amounted to $19.5 \mathrm{mmol}$, i.e. just under $7 \%$ of the incorporated amount of histidine ( $300 \mathrm{mmol})$. In the same interval, glutamate excretion rose from $1 \mu \mathrm{mol} / \mathrm{mmol}$ creatinine to $126 \mu \mathrm{mol} / \mathrm{mmol}$ creatinine and glutamine excretion from
Fig. 1 Intraoperative plasma concentrations of a histidine, b aspartate, $\mathbf{c}$ glutamate, $\mathbf{d}$ glutamine. Patients received 1.6 L cardioplegic solution at the onset of cardiopulmonary bypass, which contained 198 mM histidine for induction of cardioplegia. Values are shown as mean \pm SD. Asterisk $<0.05$ compared with the initial value. Double asterisk $<0.01$ compared with the initial value. Triple asterisk $<0.001$ compared with the initial value
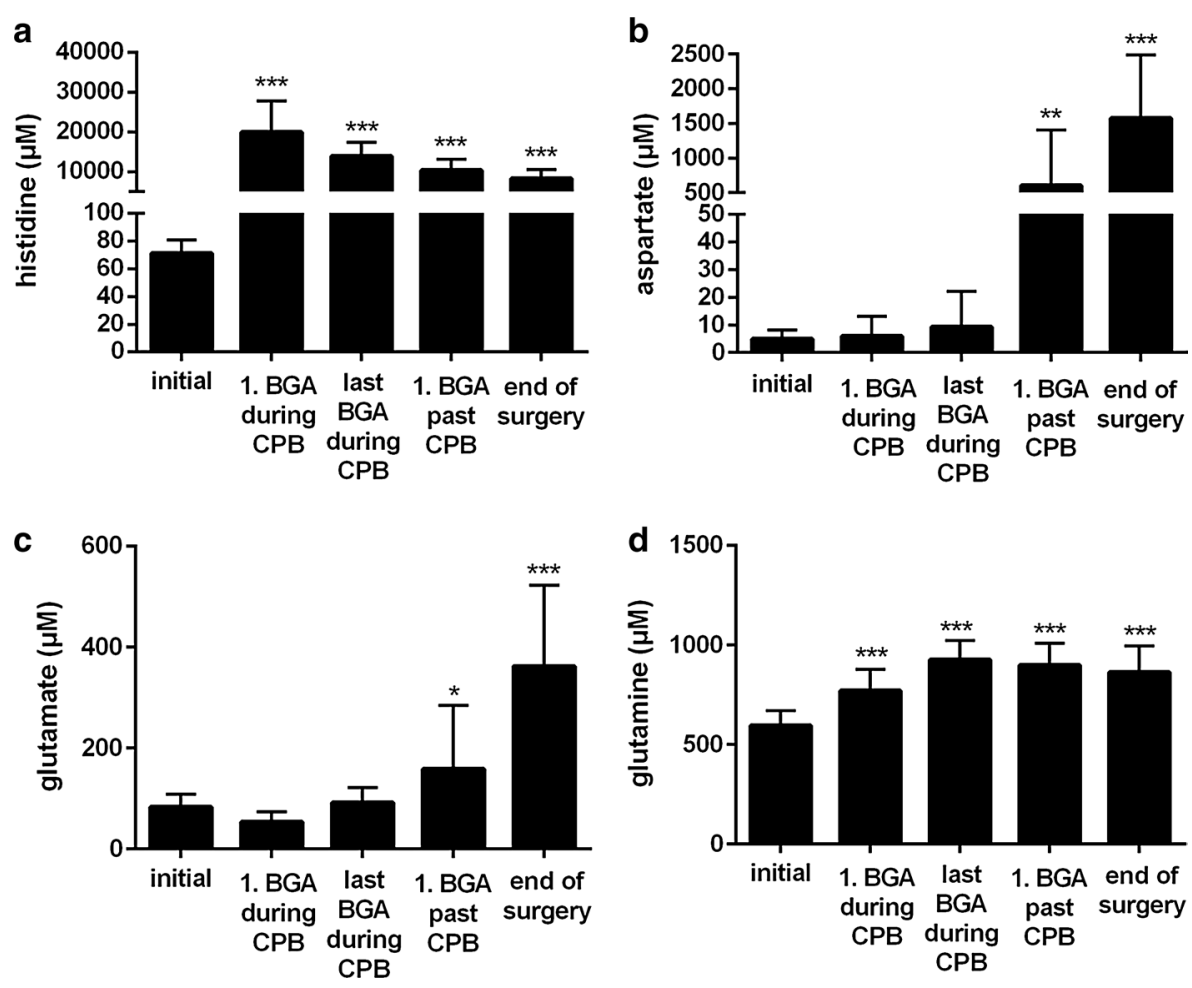
Fig. 2 Intraoperative plasma concentrations of a asparagine, b glycine, $\mathbf{c}$ alanine, $\mathbf{d}$ serine. Patients received $1.6 \mathrm{~L}$ cardioplegic solution at the onset of cardiopulmonary bypass, which contained $198 \mathrm{mM}$ histidine for induction of cardioplegia. Values are shown as mean $\pm \mathrm{SD}$. Triple asterisk $<0.001$ compared with the initial value
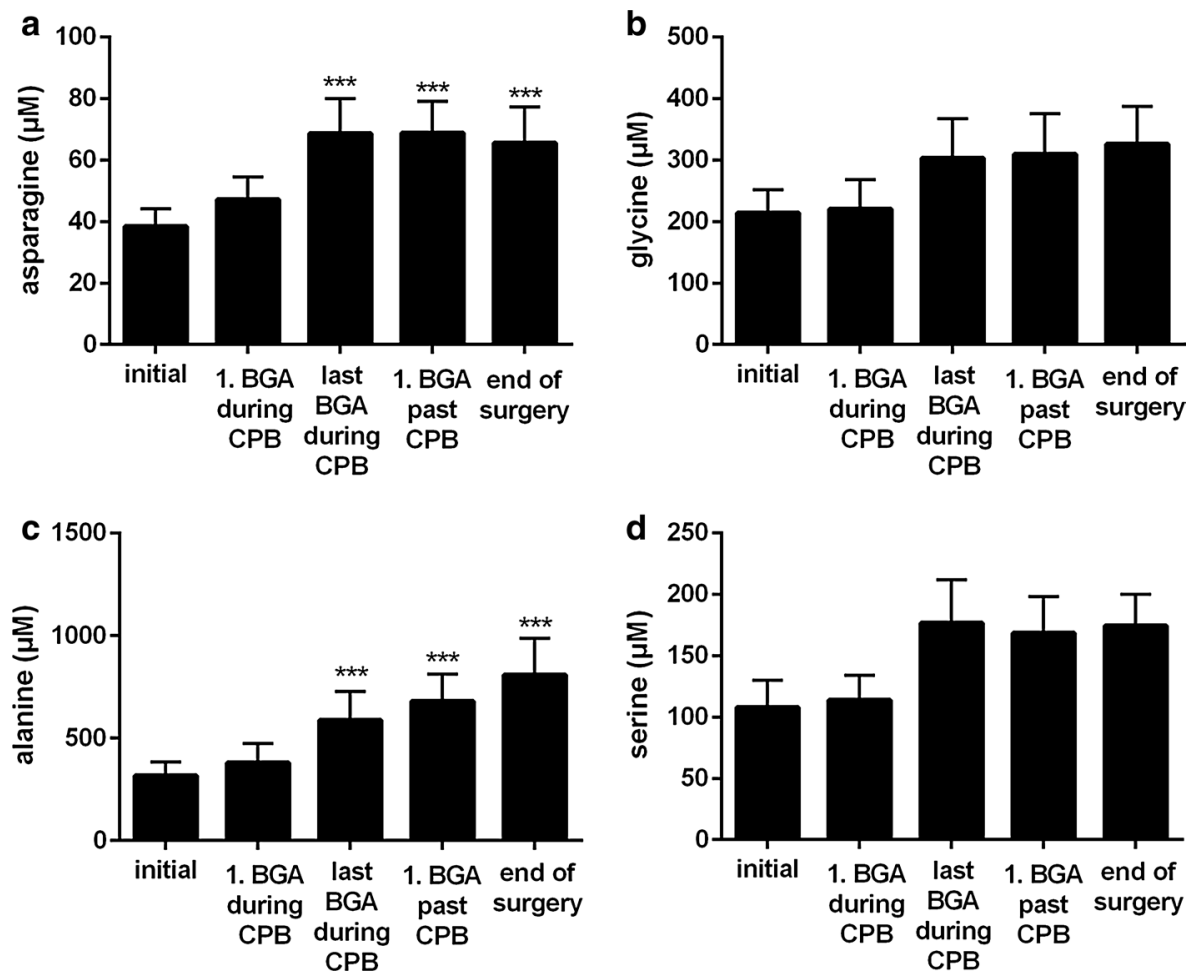

Table 1 Intraoperative plasma concentrations of different amino acids. From (Duran 2008)

\begin{tabular}{|c|c|c|c|c|c|c|}
\hline Amino acid & Initial & 1. BGA during $\mathrm{CPB}$ & Last BGA during $\mathrm{CPB}$ & 1. BGA past $\mathrm{CPB}$ & End of operation & Reference range \\
\hline Arginine $(\mu \mathrm{M})$ & $71 \pm 18$ & $70 \pm 8$ & $90 \pm 20$ & $81 \pm 21$ & $71 \pm 19$ & $15-190$ \\
\hline Leucine $(\mu \mathrm{M})$ & $135 \pm 27$ & $174 \pm 30$ & $196 \pm 36$ & $173 \pm 34$ & $159 \pm 35$ & 70-200 \\
\hline Lysine $(\mu \mathrm{M})$ & $179 \pm 21$ & $192 \pm 28$ & $222 \pm 39$ & $207 \pm 37$ & $194 \pm 31$ & $115-300$ \\
\hline Methionine $(\mu \mathrm{M})$ & $22 \pm 4$ & $24 \pm 5$ & $27 \pm 6$ & $24 \pm 5$ & $25 \pm 6$ & $10-40$ \\
\hline Ornithin $(\mu \mathrm{M})$ & $54 \pm 15$ & $49 \pm 16$ & $57 \pm 15$ & $55 \pm 17$ & $52 \pm 22$ & $50-200$ \\
\hline Phenylalanine $(\mu \mathrm{M})$ & $55 \pm 7$ & $53 \pm 9$ & $44 \pm 13$ & $42 \pm 12$ & $37 \pm 10$ & $35-85$ \\
\hline Proline $(\mu \mathrm{M})$ & $149 \pm 28$ & $151 \pm 32$ & $185 \pm 22$ & $182 \pm 30$ & $201 \pm 39$ & $97-330$ \\
\hline Tyrosine $(\mu \mathrm{M})$ & $56 \pm 11$ & $58 \pm 11$ & $54 \pm 12$ & $51 \pm 11$ & $47 \pm 9$ & $35-115$ \\
\hline Threonine $(\mu \mathrm{M})$ & $117 \pm 31$ & $131 \pm 31$ & $176 \pm 41$ & $173 \pm 36$ & $170 \pm 36$ & $60-225$ \\
\hline Valine $(\mu \mathrm{M})$ & $237 \pm 28$ & $254 \pm 37$ & $271 \pm 39$ & $263 \pm 43$ & $258 \pm 38$ & $120-340$ \\
\hline
\end{tabular}

Values are given as mean value \pm SD

$33 \mu \mathrm{mol} / \mathrm{mmol}$ creatinine to $150 \mu \mathrm{mol} / \mathrm{mmol}$ creatinine (Fig. 3c, d). Excretion of aspartate, asparagine, glycine, alanine and serine slightly increased as well but stayed within the reference range (Figs. 3b, 4a-d). Amounts of carnosine, 1-methylhistidine and 3-methylhistidine in urine were subjected to only minimal changes (data not shown).

Urea and ammonium excretion per hour increased during the time of operative procedures from 9.5 and $1.1 \mathrm{mmol} / \mathrm{h}$, respectively, at basal conditions to 10.1 and $2.6 \mathrm{mmol} / \mathrm{h}$, respectively (Fig. 5). This increase in excretion amounts to $3 \mathrm{mmol}$ urea and $8 \mathrm{mmol}$ ammonium (both median) in the intraoperative interval compared to basal excretion. The magnitude of increase in urea excretion differed among patients, thus leading to fluctuating values in the range of $2-30 \mathrm{mmol} / \mathrm{h}$. In plasma, over the course of the operation, the median of urea concentration was about $30 \mathrm{mg} / \mathrm{dL}$ (5 mM). Plasma ammonium concentration represented about $90 \mu \mathrm{g} / \mathrm{dL}(50 \mu \mathrm{M})$.

\section{Discussion}

In the human organism, histidine is degraded by two major pathways (Bender 2012a; Doetsch et al. 1987). First, it can be deaminated to glutamate via urocanic acid, which is supposed to be the dominant one. Second, it can 
Fig. 3 Excreted amounts of a histidine, $\mathbf{b}$ aspartate, $\mathbf{c}$ glutamate, $\mathbf{d}$ glutamine during the intraoperative phase. Values are shown as mean $\pm \mathrm{SD}$. Double asterisk $<0.01$ compared with the initial value. Triple asterisk $<0.001$ compared with the initial value

Fig. 4 Excreted amounts of a asparagine, $\mathbf{b}$ glycine, $\mathbf{c}$ alanine, d serine during the intraoperative phase. Values are shown as mean \pm SD

\section{a}

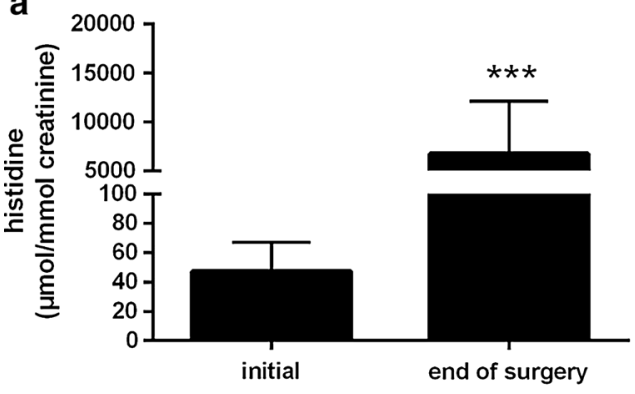

C
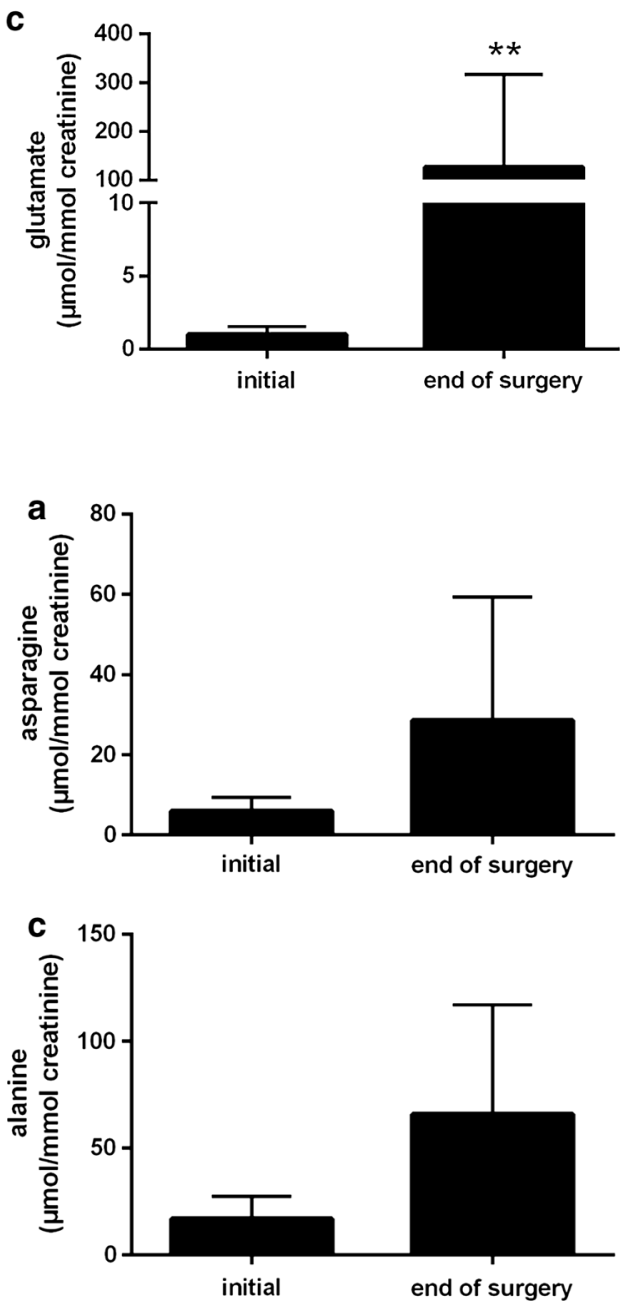

b
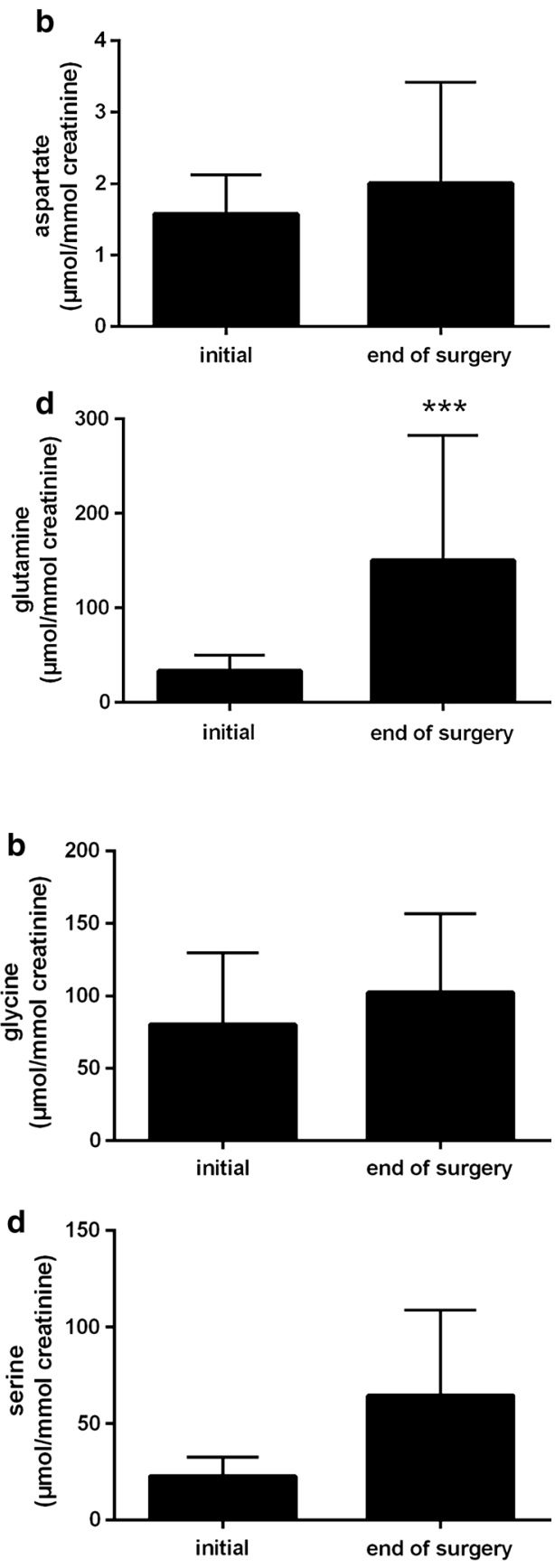

be decarboxylated to finally yield aspartate. As soon as these two pathways that ensure a specific degradation are exhausted due to a high histidine concentration in plasma, other pathways are activated in addition, yielding those amino acids with short unbranched side chains while maintaining the histidine's $\alpha$-amino-carboxylic acid group (Doetsch et al. 1987). That way, glycine, alanine or serine may be obtained, depending on the length of the hydrocarbon chain, and a possible hydroxylation.

Patients received 1.6 L Bretschneider solution on average for induction of cardioplegic arrest. Based on the applied volume and its histidine concentration of $198 \mathrm{mM}$, a total of about $300 \mathrm{mmol}$ histidine had been incorporated (Fig. 6). Assuming an estimated blood volume of approximately $5.2 \mathrm{~L}$ [calculation on the basis of the formula of Nadler (Nadler et al. 1962)], a plasma concentration of about $60 \mathrm{mM}$ would have to be expected. However, only about a third of this calculated concentration, i.e. $20 \mathrm{mM}$, was detected in plasma in accordance with two former studies (Doetsch et al. 1987; Schayani-Mühlschlegel 1990). This strongly suggests the participation of the interstitial space for distribution. Actually, inclusion of the 


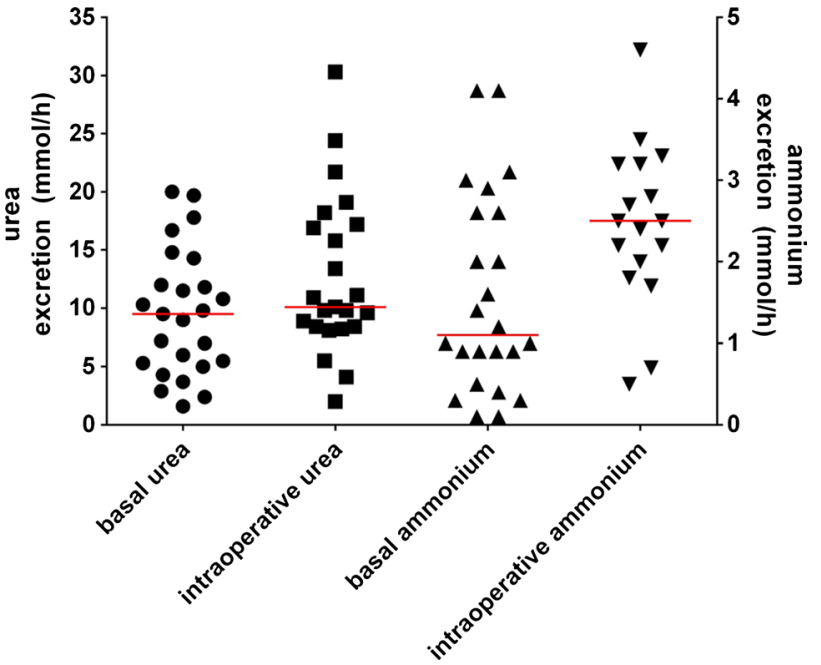

Fig. 5 Urea as well as ammonium excretion per hour from every patient at basal conditions and in the intraoperative interval, respectively. Lines represent median

entire extracellular volume for calculation [intravascular plus interstitial, approximately 2.9 -fold the blood volume (Grocott et al. 2005)] would result in a histidine concentration of approximately $20 \mathrm{mM}$. Thus, obviously, soon after incorporation (first sample during $\mathrm{CPB}$ ), an equilibrium between blood and the interstitial space had already been achieved.

The physiologic histidine concentration in plasma accounts for approximately $100 \mu \mathrm{M}$ (Table 2). Under these conditions, $5 \%$ of the filtered histidine are renally excreted due to major reabsorption in the proximal tubule (Lingard et al. 1973; Silbernagl and Volkl 1977), i.e. about $100 \mu \mathrm{mol} /$ mmol creatinine (Table 2). In the present study, attributable to the highly elevated plasma histidine level $(20 \mathrm{mM})$, the excreted amount accounted for $6800 \mu \mathrm{mol} / \mathrm{mmol}$ creatinine during the intraoperative interval. This value (equivalent to an absolute amount of $19.5 \mathrm{mmol}$ histidine) corresponds to $7 \%$ of the incorporated histidine $(300 \mathrm{mmol})$. For comparison, Doetsch et al. reported an amount of histidine excreted within the first 72 postoperative hours representing $20 \%$ of the administered dose (Doetsch et al. 1987). During the intraoperative phase, plasma histidine concentration decreased from $20 \mathrm{mM}$ to $8 \mathrm{mM}$. Renal excretion contributes only to a minor extent to this decrease $(19.5 \mathrm{mmol} /$ extracellular space of $15.1 \mathrm{~L}=1.3 \mathrm{mM}$ ). Thus, uptake into cells and metabolic degradation (see below) should mainly be responsible for the rapid decline.

In accordance with the histidine's main degradation pathways (see above), plasma concentrations of both aspartate and glutamate increased during the operation (Fig. 1b, c). Interestingly, however, the increase in plasma aspartate concentration was clearly more pronounced than the increase in plasma glutamate concentration (about $1600 \mu \mathrm{M}$ at the end of the operation, 63-times above the upper limit of the reference range vs. $360 \mu \mathrm{M}$ which is 2.8-times above the upper limit of the reference range, Table 2), although the degradation pathway yielding glutamate is supposed to constitute the major route (Ghadimi 1974; Mehler and Tabor 1953). A plausible explanation for

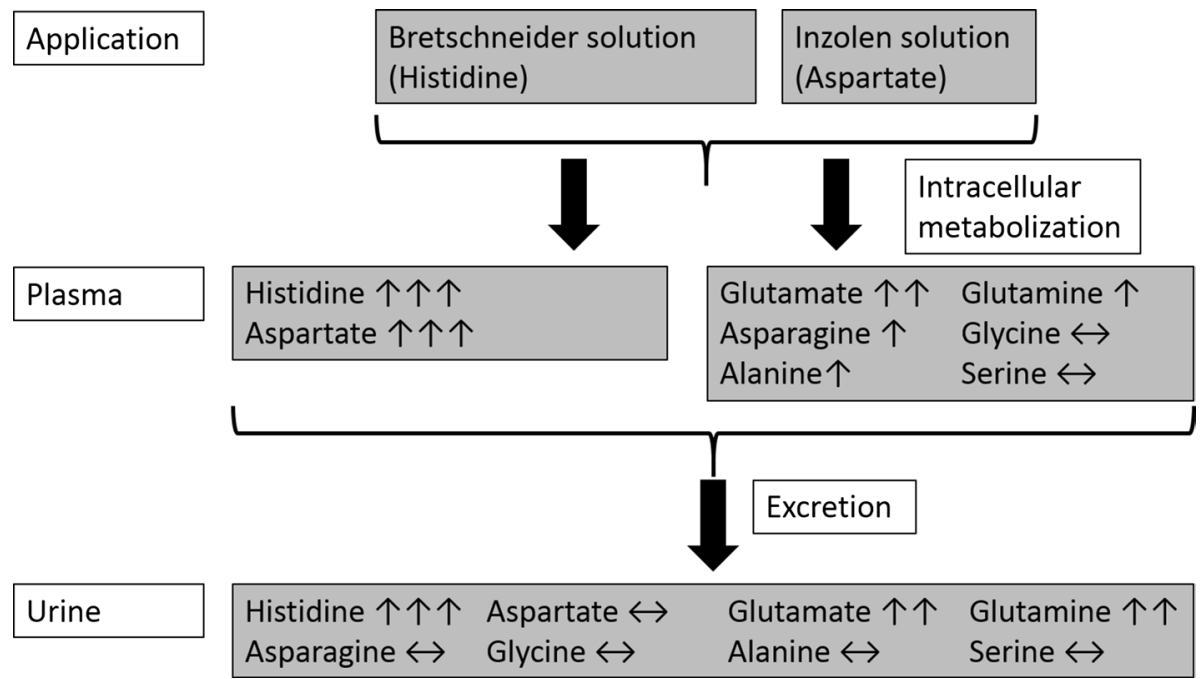

Fig. 6 Survey of application, metabolization and renal excretion of several amino acids during cardiopulmoanry bypass (CPB) in coronary artery bypass grafting patients. Patients received Bretschneider solution (main component histidine) for induction of cardioplegic arrest and Inzolen solution (main component potassium aspartate) after weaning from $\mathrm{CPB}$ to correct a shortage of potassium. In the course of intracellular metabolization, several amino acids emerge that show up in plasma, some of them are renally excreted. $\uparrow \uparrow \uparrow$, strong concentration increase; $\uparrow \uparrow$, indicates moderate concentration increase; $\uparrow$, indicates slight concentration increase; $\leftrightarrow$, indicates no change or changes staying within the reference range 
Table 2 Reference ranges of different amino acids, urea and ammonia in plasma as well as amino acids in urine

\begin{tabular}{ll}
\hline & Reference range \\
\hline Plasma & \\
Histidine & $70-125 \mu \mathrm{M}$ \\
Aspartate & $0-25 \mu \mathrm{M}$ \\
Glutamate & $10-130 \mu \mathrm{M}$ \\
Glutamine & $200-760 \mu \mathrm{M}$ \\
Asparagine & $35-75 \mu \mathrm{M}$ \\
Glycine & $150-490 \mu \mathrm{M}$ \\
Alanine & $175-580 \mu \mathrm{M}$ \\
Serine & $60-180 \mu \mathrm{M}$ \\
Urea & $17-43 \mathrm{mg} / \mathrm{dL}$ \\
Ammonia & $27-90 \mu \mathrm{g} / \mathrm{dL}$ \\
Urine $(\mu \mathrm{mol} / \mathrm{mmol}$ creatinine) & \\
Histidine & $52-162$ \\
Aspartate & $5-27$ \\
Glutamate & $5-37$ \\
Glutamine & $22-58$ \\
Asparagine & $11-53$ \\
Glycine & $83-475$ \\
Alanine & $27-76$ \\
Serine & $27-76$ \\
\hline
\end{tabular}

From Duran (2008), Thomas (1998) and Waters et al. (1967)

this unexpected behavior in plasma aspartate concentration is the application of Inzolen (Fig. 6). In conjunction with cardiac surgery, Inzolen solution, consisting mainly of racemic potassium aspartate and further trace elements, is usually applied to correct a shortage of potassium. In the present study, due to the solution's composition, patients received approximately $24 \mathrm{mmol}$ aspartate after weaning from CPB this way. Despite the aspartate's highly elevated plasma level, urine analysis revealed only minor excretion (Fig. 3b), but enhanced excretion of glutamate $(126 \mu \mathrm{mol} /$ mmol creatinine at the end of operative procedures, 3-times the upper limit of the reference range, Fig. 3c; Table 2). Because aspartate and glutamate possess the same net charge at physiological $\mathrm{pH}$, they are reabsorbed by the same carrier in the proximal tubule [in the case of aspartate independent of the isomer (Silbernagl 1983; Silbernagl and Volkl 1983)]. Obviously, reabsorption of aspartate is preferred which is in line with the higher affinity of the carrier for aspartate $\left(\mathrm{K}_{\mathrm{M}} 0.10 \mathrm{mM}\right.$ for aspartate vs. $0.17 \mathrm{mM}$ to $0.50 \mathrm{mM}$ for glutamate, both determined in the rat) (Silbernagl 1981, 1983).

Those amino acids having been formed by side chain conversion while maintaining the histidine's original $\alpha$-amino-carboxylic acid group, i.e. glycine, alanine and serine, also increased in plasma in the course of the operation, although variable in magnitude, with glycine and serine staying within the reference interval (Fig. 2b-d; Table 2). The increase of alanine $(300 \mu \mathrm{M}$ to $800 \mu \mathrm{M}$ at the end of the operation, 1.4-times above the upper limit of the reference range, Table 2) was plainest among those three amino acids, perhaps either due to the transamination reaction with glutamate or with histidine itself. The latter reaction occurs rarely under physiologic conditions but becomes more important in diseases associated with histidinemia (Bender 2012a), characterized by histidine plasma levels up to $1.8 \mathrm{mM}$ (Ghadimi 1974; Virmani and Widhalm 1993). In accordance with the elevated concentrations in plasma, urinary excretion of glycine, alanine and serine increased slightly during the intraoperative interval, but stayed within the reference interval (Fig. 4b-d; Table 2). Glutamine as well as asparagine possess the capability to accommodate an additional amino group, therefore representing the possibility to store further nitrogen. However, the plasma concentrations of glutamine as well as asparagine increased only moderately during the operation (Figs. 1d, 2a). For glutamine, this probably results from continuous catabolism for the purpose of ammonium synthesis and an increased excretion $(150 \mu \mathrm{mol} / \mathrm{mmol}$ creatinine, 2.6-times the upper limit of the reference range; Fig. 3d; Table 2). Increased glutamine excretion might arise from end product inhibition of glutamine and glutamate catabolism by alpha-ketoglutarate (Yao et al. 2012). Carnosine ( $\beta$-alanyl-histidine, $<5 \mu \mathrm{M}), 1$-methylhistidine as well as 3-methylhistidine (both $<3 \mu \mathrm{M}$ ) as further degradation products of histidine (Bender 2012a) stayed below the limit of quantification in plasma and were comparable to baseline conditions at the end of operative procedures in urine (data not shown). Thus, these pathways of histidine metabolism remained unused.

Alterations in glutamate, glutamine, alanine, asparagine and aspartate may arise from histidine metabolism. In addition, aspartate is applicated with the Inzolen solution. All are, directly or indirectly, glucoplastic amino acids (Bender 2012a, b). Therefore, they can be used for gluconeogenesis that is per se energy consuming. Energy consumption of asparagine, aspartate, glutamine and glutamate is smaller during this process compared to that of alanine, since pyruvate deriving from alanine degradation must first be carboxylated to oxaloacetate, which costs additional two molecules ATP per mol glucose. In contrast, metabolism of the aforementioned amino acids directly yields oxaloacetate or alpha-ketoglutarate that is converted to oxaloacetate via the citric acid cycle. Alpha-ketoglutarate deficiency in cardiac tissue occurs rapidly during ischemia (Peuhkurinen et al. 1983). Provision of alpha-ketoglutarate (as an additive in blood cardioplegia) has been shown to attenuate myocardial ischemic injury in patients undergoing coronary revascularization (Kjellman et al. 1995). Hence, exogenous supply might preserve myocardial oxidative 
capacity. In addition, it may help to minimize postoperative muscle catabolism (see below) (Wernerman et al. 1990). Thus, the addition of $1 \mathrm{mM}$ alpha-ketoglutarate to the cardioplegic solution seems beneficial, despite the possible conversion of amino acids arising from histidine metabolism into alpha-ketoglutarate in the later course. The cardioplegic solution also contains $2 \mathrm{mM}$ tryptophan. In the course of tryptophan metabolism, the antioxidant melatonin might be formed but also nicotinamide adenine dinucleotide might even increase which has also been reported to act as an antioxidant (Kirsch and de Groot 2001). Due to the melatonin's inherent antioxidant function (Tan et al. 2002) but also the induction of antioxidant enzymes, it can exert cardio-protective effects against amongst others ischemia/reperfusion injury (Giacomo and Antonio 2007; Reiter and Tan 2003). Since during temporary cardioplegia the myocardium becomes ischemic very easily, this might have an appreciable contribution to myocardial protection during this phase as well.

The entire amount of histidine having been metabolized during the intraoperative period should be reflected by the differences in amino acid as well as urea and ammonium concentrations/amounts before (baseline values) and at the end of the operation in plasma as well as in urine, averaging $30 \mathrm{mmol}$ in total. In this regard, the amount of further amino acids in urine except for histidine is negligible in terms of quantity. Of these $30 \mathrm{mmol}$, two-thirds account for the rise in several amino acids in plasma $(19 \mathrm{mmol}$ altogether) and one-third for elevation of ammonium ( $8 \mathrm{mmol})$ plus urea $(3 \mathrm{mmol})$ excretion. Plasma urea and ammonia concentrations were in accordance with physiological values in the literature (Table 2), as expected for substances that are obligatory for excretion by urine. Hence, metabolism in this intraoperative phase is small, but principally, it is supposed to continue in the postoperative phase. In the special case of aspartate, this amino acid was left out of consideration. Due to Inzolen application beginning after weaning from $\mathrm{CPB}$, the amount of aspartate rose continuously towards the end of the intraoperative period. For this reason, a considerable share originating from histidine metabolization is unlikely.

Apart from the $\alpha$-amino group, every histidine possesses two additional nitrogen atoms located in the imidazole ring. In the course of metabolism, this nitrogen should be excreted either as ammonium ions or as urea in the long term. Nitrogen excretion per se is intimately linked to systemic acid-base status, since generation of urea is bicarbonate consuming (Han 2011; Meijer 1995; Pitts 1964), whereas ammonium is mainly obtained by deamination reactions from glutamine, glutamate or histidine (Han 2011; Pitts 1964; Weiner et al. 2015). As it is common for amino acid metabolism, the histidine's $\alpha$-amino group is converted to urea together with bicarbonate derived from the degradation of the remaining $\alpha$-keto acid, thus being neutral as regards systemic acid-base homeostasis. The excretion of a surplus of $3 \mathrm{mmol}$ urea (see above) should result in an additional base deficit of only $-1 \mathrm{mEq} / \mathrm{L}$. Thus, in relation to acute metabolic acidosis originating from massive dilution of endogenous bicarbonate based on administration of both the priming and the cardioplegic solution (Teloh et al. 2015), the impact of nitrogen metabolism on acid base status in the intraoperative phase is minor. Due to persistent metabolism in the postoperative phase, however, the acidifying effect caused by enhanced urea excretion might get more pronounced over the course of time. In contrast, metabolization of infused aspartate (24 mmol) as part of the Inzolen solution should have an alkalizing effect in general based on its additional carboxyl group.

Subsequent to severe trauma or operations, amongst others, a stress-induced increase in sympathetic nervous activity is observed, resulting in a hypermetabolic state, the so-called postaggression syndrome (Sachs et al. 1988). One of its characteristics is an increased gluconeogenesis from glucoplastic amino acids originating from enhanced protein degradation in skeletal muscle. Therefore, in such a condition, nitrogen balance is principally negative. Some evidence exist, that postaggression syndrome might be mitigated by amino acid administration. A benefit resulting from thereof is supported by a study of Umenai et al. that was able to show positive effects of perioperative amino acid infusion in patients undergoing off-pump CABG, resulting in a significantly shorter duration of postoperative mechanical ventilation as well as intensive care unit stay (Umenai et al. 2006). Therefore, intraoperative provision of several amino acids arising from histidine metabolism ( $19 \mathrm{mmol}$ in the present study) might achieve a similar result, especially since many of them represent glucoplastic amino acids (see above). Endogenous protein sources like skeletal muscle might be spared from degradation this way. Because the provision of several amino acids takes place before the onset of postaggression syndrome, this application's effect might be particularly beneficial.

In conclusion, in patients undergoing $\mathrm{CABG}$, receiving approximately $1.6 \mathrm{~L}$ Bretschneider solution, a very substantial elevation of plasma histidine concentration was observed a few minutes after onset of CPB. Of the incorporated amount of $300 \mathrm{mmol}$ histidine approximately $7 \%$ were excreted without prior metabolization. In addition, about $10 \%$ were metabolized, mostly being converted into other amino acids. Therefore, the influence on acidbase homeostasis originating from nitrogen metabolism is minor. Moreover, altered amino acid levels in plasma may have beneficial effects on postaggression syndrome in the postoperative phase. 
Acknowledgments We are greatly indebted to Markus Mallek for the excellent conduction of amino acid measurements.

\section{Compliance with ethical standards}

Funding No external funding was received.

Conflict of interest The authors declare that they have no conflict of interest.

Ethical approval All procedures performed in studies involving human participants were in accordance with the ethical standards of the national research committee and with the 1964 Helsinki declaration and its later amendments or comparable ethical standards.

Informed consent was obtained from all individual participants included in the study.

This article does not contain any studies with animals performed by any of the authors.

Open Access This article is distributed under the terms of the Creative Commons Attribution 4.0 International License (http://creativecommons.org/licenses/by/4.0/), which permits unrestricted use, distribution, and reproduction in any medium, provided you give appropriate credit to the original author(s) and the source, provide a link to the Creative Commons license, and indicate if changes were made.

\section{References}

Bender DA (2012a) Histidine. In: Bender DA (ed) Amino Acid Metabolism. 3 edn. Wiley-Blackwell, pp 305-322

Bender DA (2012b) Nitrogen balance and protein turnover-protein and amino acids in human nutrition. In: Bender DA (ed) Amino Acid Metabolism. 3 edn. Wiley-Blackwell, pp 67-104

Beyersdorf $\mathrm{F}$ et al (1990) Clinical evaluation of hypothermic ventricular fibrillation, multi-dose blood cardioplegia, and single-dose Bretschneider cardioplegia in coronary surgery. Thorac Cardiovasc Surg 38:20-29

Careaga G, Salazar D, Tellez S, Sanchez O, Borrayo G, Arguero R (2001) Clinical impact of histidine-ketoglutarate-tryptophan (HTK) cardioplegic solution on the perioperative period in open heart surgery patients. Arch Med Res 32:296-299

Doetsch N, Zerkowski H-R, Weyer B, Reidemeister JC (1987) Histidin-Elimination nach Inkorporation histidingepufferter kardioplegischer Lösung. Thorac Cardiovasc Surg 35:44-45

Duran M (2008) Amino acids. In: Blau N, Duran M, Gibsen KM (eds) Laboratory guide to the methods in biochemical genetics. Springer, Berlin, pp 53-88

Ghadimi H (1974) Histidinemia: emerging clinical picture. In: Nyhan WL (ed) Heritable disorders of amino acid metabolism: patterns of clinical expression and genetic variation. John Wiley \& Sons, New York, pp 265-292

Giacomo CG, Antonio M (2007) Melatonin in cardiac ischemia/reperfusion-induced mitochondrial adaptive changes. Cardiovasc Hematol Disord: Drug Targets 7:163-169

Grocott MP, Mythen MG, Gan TJ (2005) Perioperative fluid management and clinical outcomes in adults. Anesth Analg 100:1093-1106

Han KH (2011) Mechanisms of the effects of acidosis and hypokalemia on renal ammonia metabolism Electrolyte. Blood Press 9:45-49

Kirsch M, de Groot H (2001) NAD(P)H, a directly operating antioxidant? FASEB J 15:1569-1574
Kjellman U et al (1995) Alpha-ketoglutarate for myocardial protection in heart surgery. Lancet 345:552-553

Kober IM, Obermayr RP, Brull T, Ehsani N, Schneider B, Spieckermann PG (1998) Comparison of the solutions of Bretschneider, St. Thomas' Hospital and the National Institutes of Health for cardioplegic protection during moderate hypothermic arrest. Eur Surg Res 30:243-251

Korun O, Özkan M, Terzi A, Askin G, Sezgin A, Aslamaci S (2013) The comparison of the effects of Bretschneider's histidine-tryptophan-ketoglutarate and conventional crystalloid cardioplegia on pediatric myocardium at tissue level. Artif Organs 37:76-81

Lingard J, Rumrich G, Young JA (1973) Kinetics of L-histidine transport in the proximal convolution of the rat nephron studied using the stationary microperfusion technique. Pflugers Arch 342:13-28

Mehler AH, Tabor H (1953) Deamination of histidine to form urocanic acid in liver. J Biol Chem 201:775-784

Meijer A (1995) Urea synthesis in mammals. In: Walsh P, Wright P (eds) Nitrogen metabolism and excretion. CRC Press, Boca Raton, pp 193-204

Nadler SB, Hidalgo JH, Bloch T (1962) Prediction of blood volume in normal human adults Surgery 51:224-232

Peuhkurinen KJ, Takala TE, Nuutinen EM, Hassinen IE (1983) Tricarboxylic acid cycle metabolites during ischemia in isolated perfused rat heart. Am J Physiol 244:H281-H288

Pitts RF (1964) Renal production and excretion of ammonia. Am J Med 36:720-742

Reiter RJ, Tan DX (2003) Melatonin: a novel protective agent against oxidative injury of the ischemic/reperfused heart Cardiovasc Res 58:10-19

Sachs M, Asskali F, Forster H, Ungeheuer E (1988) Postaggression metabolism following laparotomy and thoracotomy. Chirurg 59:24-33

Sakata J, Morishita K, Ito T, Koshino T, Kazui T, Abe T (1998) Comparison of clinical outcome between histidine-triptophanketoglutalate solution and cold blood cardioplegic solution in mitral valve replacement. J Card Surg 13:43-47

Schayani-Mühlschlegel R-P (1990) Abbauwege des Histidins nach Inkorporation durch HTK-Kardioplegie. University Duisburg-Essen

Scrascia G et al (2011) Myocardial protection during aortic surgery: comparison between Bretschneider-HTK and cold blood cardioplegia. Perfusion 26:427-433

Silbernagl S (1981) Renal transport of amino acids and oligopeptides. In: Greger R, Lang F, Silbernagl S (eds) Renal transport of organic substances. Springer, Berlin, pp 93-117

Silbernagl S (1983) Kinetics and localization of tubular resorption of "acidic" amino acids. A microperfusion and free flow micropuncture study in rat kidney Pflugers Arch 396:218-224

Silbernagl S, Volkl H (1977) Amino acid reabsorption in the proximal tubule of rat kidney: stereospecificity and passive diffusion studied by continuous microperfusion. Pflugers Arch 367:221-227

Silbernagl S, Volkl H (1983) Molecular specificity of the tubular resorption of "acidic" amino acids. A continuous microperfusion study in rat kidney in vivo. Pflugers Arch 396:225-230

Tan DX et al (2002) Chemical and physical properties and potential mechanisms: melatonin as a broad spectrum antioxidant and free radical scavenger. Curr Top Med Chem 2:181-197

Teloh JK, Dohle D-S, Sönmez S, Tsagakis K, Verhaegh R, Petersen M, Jakob H, de Groot H (2015) Transient dilutional acidosis but no lactic acidosis upon cardiopulmonary bypass in patients undergoing coronary artery bypass grafting. Arch Med Sci. doi:10.5114/aoms.2016.58144

Thomas L (1998) Metabolic parameters. In: Thomas L (ed) Clinical laboratory diagnostics. TH Books Verlagsgesellschaft, Frankfurt, p 186 
Umenai T, Nakajima Y, Sessler DI, Taniguchi S, Yaku H, Mizobe T (2006) Perioperative amino acid infusion improves recovery and shortens the duration of hospitalization after off-pump coronary artery bypass grafting. Anesth Analg 103:1386-1393

Virmani K, Widhalm K (1993) Histidinemia: a biochemical variant or a disease? J Am Coll Nutr 12:115-124

Waters WE, Greene WJ, Keyser JW (1967) Plasma urea concentrations in the general population: comparison with 'hospital normal values'. Postgrad Med J 43:695-700
Weiner ID, Mitch WE, Sands JM (2015) Urea and ammonia metabolism and the control of renal nitrogen excretion. Clin J Am Soc Nephrol 10:1444-1458

Wernerman J, Hammarqvist F, Vinnars E (1990) Alpha-ketoglutarate and postoperative muscle catabolism. Lancet 335:701-703

Yao K et al (2012) Alpha-ketoglutarate inhibits glutamine degradation and enhances protein synthesis in intestinal porcine epithelial cells. Amino Acids 42:2491-2500 